\title{
Analysis of Intensity of Intra-Regional Trade in GCC Countries, 1998-2008
}

\author{
Ahmed Saddam Abdul Sahib and Fatimah Kari
}

\begin{abstract}
This paper addresses the intra-regional trade of the countries of the Gulf Cooperation Council (GCC), namely, the United Arab Emirates, Bahrain, Saudi Arabia, Oman, Qatar and Kuwait. We have found that the intra-regional trade is still at a modest level, where the trade intensity index showed negative signals except the UAE, and Saudi Arabia. The study concludes that the unified economic policy of the GCC countries has not achieved its target in terms of increasing the level of intra trade which implies a high reliance on oil export revenues.
\end{abstract}

Index Terms-Economic growth, GCC, GDP, intensity trade.

\section{INTRODUCTION}

The role of trade, regionally and internationally, as an engine of economic growth has increased considerably, particularly in countries that follow a policy of encouraging exports, where it leads to an increase in the gross domestic product level and improved terms of trade, which, in turn, reflects achieving acceptable economic growth. Therefore, many scholars have emphasized the positive role of improving the level of foreign trade and then economic openness

However, the foreign trade commodity is one of the most important factors for economic growth in GCC countries, especially for Saudi Arabia as a main producer and exporter of crude oil, as all GCC countries characterized in a high reliance on the world by importing most of their capital and consumer goods.

\section{REVIEW OF LITERATURE}

Many studies have emerged addressing the role of foreign trade, the most important studies are those of Fischer, which analysed the relationship between the policy of import substitution and its positive impact on growth after World War II, and encouraged export growth. In this respect, Fischer confirms the role of economic policy in promoting export levels and enhancing the rate of growth [1]. He reports that a greater degree of economic openness will promote growth and income level as well, as the open countries have increased their economic growth rate by $2 \%$ compared with closed countries.

This positive effect occurs through the increased level of trade. Fisherasserts that countries wishing to grow must be integrated into the globaleconomy to take advantage of the foreign market and flows of foreign investment. Moreover,

Manuscript received March 29, 2012; revised May 05, 2012.

A. S. A. Sahib is with Economics and Administration University of Malaya, Kuala Lumpur (email: ahmed_saddam@live.com).
Fisher stresses on countries that wish to grow must be integrated into the global economy to take advantage of the foreign market, and foreign investment flows. However, Promotion of exports is a part of trade policy, and can be considered as a tool of funding imports, where one of studies shows that the experience of 25 developing countries have witnessed the fastest economic growth rates over the period 1965-1994 and which were characterized as high level (10\%) [2].The main notion of this study is that it confirms the significant role of exports to stimulate economic activities and enhance the level of growth. Alcala and Ciccone found that trade and local markets were the major determinants of economic growth over the period 1960-1996 [3]. Their study tests trade openness, which they consider as an appropriate measure of trade. In this study, the average growth rate of income per capita is the dependent variable of the study's model, while trade openness, local market size, institutional quality, initial income per capita are the independent variables.

Spanue affirmed that the liberalization of foreign trade leads to a positive impact on the economy and may lead to economic growth [4], where the critical issue in this growth is the economic and trade policies followed by the state to determine the trend of economic growth. The main point in this study concerns foreign trade and the importance of the lifting of trade restrictions as a significant process to obtain WTO membership. These steps are consistent with the conditions of the International Monetary Fund (IMF) and World Bank (WB) for achieving economic reformation and enhancing the level of foreign trade. Vlad Spanu suggested that to increase the level ofexports in developing countries is mainly associated with the transnationalcorporations nationalities (TNCs), which holds that the share of foreign firms intotal exports achieved rates as high as (90\%) in Ireland, $(80 \%)$ in Hungary, Poland, $(56 \%)$ China, Costa Rica (50\%), Switzerland (47\%), Sweden (39\%), and Mexico(31\%).

Sohn analysed Korea's trade pattern based on the gravity model [5]. His study suggests possible ways to expand foreign trade by identifying the important factors that determine Korea's bilateral trade flows. This study added new independent variables, such as the trade conformity index and APEC membership, in order to examine the trade patterns of Korea in terms of following the Heckscher-Ohlin model or the differentiated product model [6]. However, this study focused on the positive effect of foreign trade on economic growth of developing countries through its role in transferring the technology to countries that imported capital goods. This study confirmed the importance of developing countries to expand trade relations withdeveloped countries.In addition, this study confirmed the expansion of 
trade relations between developing and developed countries. Furthermore, it reported that the open trade policy is a good motivation that promotes economic growth resulting from foreign trade, which could lead to sustainable economic growth. This study depends on the formulation of a standard formin which researchers found that trade openness significantly promoteseconomic growth. Thissupports that the expansion of economicrelations between developing and developed countries has been delayed by the need to acquire the technologyneeded to achieve economic growth. The study was based on Endogenous growth theories, which suggest that countries benefit from foreign trade through the import of capital goods, and advanced technology. Carrillo and $\mathrm{Li}$ analysed the importance of trade agreements in enhancing intra-industrial trade of Latin American countries over the period 1980-1997[7]. The study reports that increasing the level of intra-trade in these countries is attributed to the role of intra-industrial trade, which witnessed a significant increase during the said period. Furthermore, it tested the effectiveness of trade agreements in raising the trade level by applying a gravity model of bilateral trade flows. It found that these trade agreements have had an impact on the dynamism of intra-regional trade and on the high increase of intra-industrial. In addition, it confirms that distance has a statistically significant effect, and that size of economy is considered a main determinant of trade.

\section{Methodology}

This study is based on an analysis of the data to extrapolate the reality of GCC economies for the period 1998-2008. Also, in this approach, we will depend on graphs that are associated with the analysis of the study. Regarding the commercial relationship between GCC countries, we will adopt a mathematical formulation [8] to measure and assess the intensity of Intra-trade of GCC countries, in order to identify the reality of regional trade between these countries, this formulation is

$C i=\left\{\left[X_{G C C}-M_{G C C}\right] /[X\right.$ total + M total $\left.]\right\}-\left\{\left[X_{G C C}+M_{G C C}\right]\right.$ $/[X$ total $+M$ total $] *[X$ total $-M$ total $] /[X$ total $+M$ total]\}

Where: Ci: Intensity of regional trade of the country (i) with other GCC countries in the net total export.

$X_{G C C}$ : Intra-export from country (i) to other GCC countries.

$M_{G C C}$ : Intra-import from country (i) to other GCC countries.

$X$ total: Total export of the country (i) to the world countries.

$M$ total: Total import of the country (i) from the world countries.

By the formulation above, if $(\mathrm{Ci})$ is positive that means the country (i) has dense exports with GCC and other countries, and vice versa. When $(\mathrm{Ci})$ is negative that means the country (i) has dense imports with GCC and other countries. The country that has the highest density of trade over the period 1998-2008 will be considered as the leading market in GCC countries.

\section{REALITY OF INTRA- REGIONAL TRADE IN GCC COUNTRIES}

average of intra-trade in GCC countries ranges between
$6 \%-14.6 \%$ [9] for the total foreign trade over.These modest proportions are attributed to the similarity of production patterns in these countries, which makes its trade a limited activity in general.

During the period 1998-2008, the average of intra-trade is about USD 29,473.6 million [10]. This represents $8.6 \%$ of the average total of non-oil foreign commodity, which amounted to USD 344,239.21 million, where the value of imports is about USD 154,175.58 million, and the value of exports is USD 190,063.63 million. - . However, we noted that both Saudi Arabia and the United Arab Emirates have the biggest share of the average of total intra-exports, which amounted to USD 9454.97 million, and USD 5556.78 million, respectively. The proportion of intra-exports is estimated to be $52 \%$ and $30 \%$, respectively, during the period 1998-2008(*).

The most important exported commodities are industrial products, and natural resources. The industrial exports of Saudi Arabia are estimated to be $63 \%$, followed by natural resources $(29 \%)$ and the remaining percentage, $8 \%$ represents agricultural products [11]

According to the above, we see that increasing the level of intra-exports is related to the level of investment of non-oil sectors. However, we see that foreign direct investment is a good way within this framework in order to achieve rapid economic growth. Also, the low level of intra-exports in GCC countries refers to the weakness of diversification. This could be enhanced through using the high level of oil revenue to increase the non-oil industries and decrease the leakage of a large part of the income of these countries. Therefore, the important issue is investing the oil revenue in non-oil projects. This will significantly contribute to increasing the level of value added and diversifying the production structure in order to meet the local needs, with the possibility of exporting the surplus commodities to other GCC countries, which helps to increase the level of total intra-exports. Moreover, we note also that UAE has reached the first rank in terms of its total intra-imports, which amounted to USD 3146.35 Million and represents $28 \%$ of the total intra-GCC imports, in which chemical products is the most important commodity imported by the UAE from Saudi Arabia, which represents $20 \%$ of the total intra-imports of GCC countries on average for the period 1998-2008. Also, both Oman and Qatar represent 15\%, 14\%, respectively, followed by Kuwait and Bahrain in proportions $13.5 \%$ and $9.5 \%$, respectively [12].

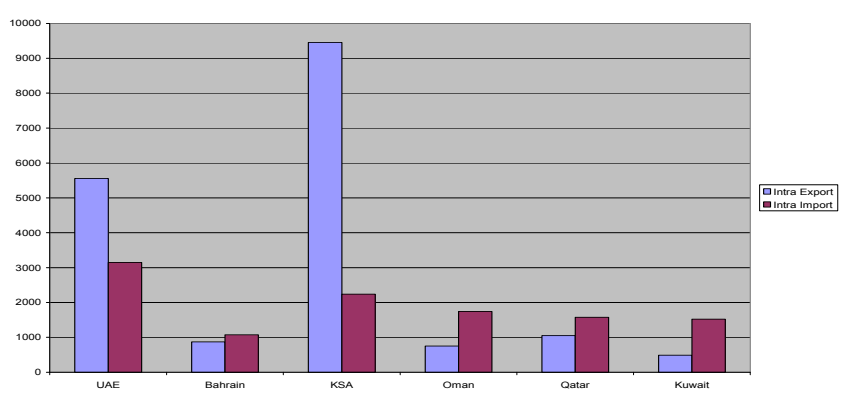

Fig. 1. Intra-Export and Import , 1998-2008 (Million USD).

${ }^{(*)}$ All ratios of this study have calculated by the researcher based on official data of study. 
SourceGCC, Secretariat general (2001-2008), Statistical bulletin.League of Arab states, et.al (2001-2003,2009), (In Arabic) Joint Arab economic report, Abu Dhabi.

United Nations, ESCWA (2009) External trade bulletin of the ESCWA region, eighteenissue, New York, pp44-46.

Fig. 1 clearly confirms that both Saudi Arabia and the United Arab Emirates represent the main market of intra-trade of the GCC countries for the period 1998-2008, whereas Oman is the first trade partner of each Furthermore, this fact is clearer when we compare GCC's intra-trade with their foreign trade commodity during the said period, where the average intra-trade represents $8.6 \%$ of the total foreign trade during the period 1998-2008, which shows a weakness of intra-trade commodities in these countries. The data of study illustrated the share of GCC countries in its contribution to the total intra-trade as a percentage of total foreign trade, the high ratio in Oman, $14.6 \%$, is because the Omani economy has a high trade level with the rest of the GCC countries, particularly Saudi Arabia and the United Arab Emirates, which means there are strong commercial relationships between Oman and these countries. By the same reason, Bahrain ranks in the second level, which amounted to 13\%, while Saudi Arabia and Qatar are dominating on 11.6\% and $11 \%$, respectively. We note that both the United Arab Emirates and Kuwait represent the lowest level in total contribution of intra-trade $(6 \%)$ and (4\%), respectively, as a percentage of average of total foreign trade. Figure (2) confirms that the United Arab Emirates and Saudi Arabia represent the largest economic power in the Gulf Cooperation Council, in both, foreign trade and intra-trade The main issue that must be emphasized is that intra-trade in this study only includes domestic produced goods -as was mentioned already -and does not include transit. The researcher has excluded the transit trade and crude oil to show the real situation of intra-trade.

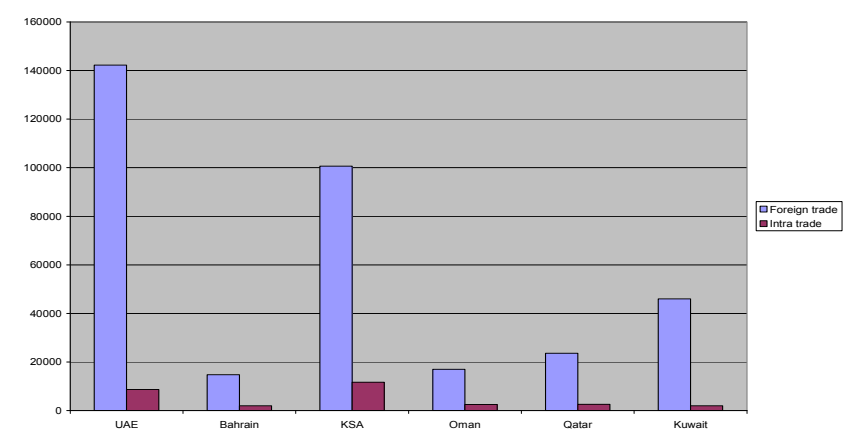

Fig. 2. Foreign and Intra-trade commodity of GCC, on average 1998-2008 (Million USD).

Source:GCC, Secretariat general (2001-2008), Statistical bulletin.

League of Arab states, et.al (2001-2003,2009), (In Arabic) Joint Arab economic report, Abu Dhabi.

United Nations, ESCWA (2009) External trade bulletin of the ESCWA region, eighteenissue, New York, pp44-46.

In addition, Fig. 2 verifies that Bahrain and Oman have the lowest foreign trade level, and that Kuwait has heavy reliance on foreign trade compared with its small intra-trade. Also, the situation is similar in Qatar, its intra-trade level is better than Kuwait. However, the UAE economy has a high dependence on foreign trade, which represents $41 \%$ of the total average of foreign trade in the GCC countries for the period 1998-2008 (29.5\%). Furthermore, we see that the average of intra-trade of the UAE amounted to $29.5 \%$ over the period of study. Therefore, the UAE is considered a vital economy in terms of its relation with the GCC and non-GCC countries. In other words, the UAE economy is a more open economy towards the world market in comparison with the other GCC countries.In respect of Qatar and Kuwait, the foreign trade commodity represents $7 \%$ and $13 \%$, respectively. While the intra-trade amounted to $9 \%, 7 \%$ of the total trade volume between GCC countries. Therefore, we can say that Qatar has more reliance on intra-trade compared to Kuwait. In other words, Kuwait depends on other countries outside of the GCC to meet its commodity needs. Also, the UAE and Saudi Arabia are the major economies in the GCC in general, which are controlling the largest share in respect of foreign and intra-trade, as mentioned before 1998-2008. According to previous analysis, and to determine the intensity of intra-trade in the GCC countries during the period 1998 2008 , and by using the methodology of this study, we obtained the following result:

\section{UAE:}

\section{$C i=[2410.43 / 142255.28]-([8703.13 / 142255.28] *$ \\ [9368.94 / 142255.28]) \\ $\boldsymbol{C} \boldsymbol{i}=\mathbf{0 . 0 1 2 9}$}

The above result indicates that the UAE has a density in its intra-export commodity, which implies that the UAE economy has achieved a surplus in the commodity production during the period 1998-2008. Furthermore, it increased the growth level of intra-trade over the same period; in other words, the UAE economy achieved a competitive advantage in its intra-export more than its intra-imports.

\section{Bahrain:}

\section{$\overline{C i}=[-200.98 / 14729.69]$ - ([1946.78 / 14729.69] * \\ [4152.57 / 14729.69]) \\ $\mathrm{Ci}=\mathbf{- 0 . 0 5 0 8}$}

The negative result above shows that Bahrain has a density in its intra-import, which confirms its increased reliance on the other GCC countries for obtaining its commodity needs.

\section{Saudi Arabia:}

$\overline{C i=[7212.55} / 100640.64]-([11697.03 / 100,640.64] *[-$ 2278.92 / 100,640.64])

\section{$\mathrm{C} \boldsymbol{i}=\mathbf{0 . 0 7 4 2}$}

$C i==0.0742$. The positive result above confirms that Saudi Arabia has a large concentration in intra-export and is superior to the United Arab Emirates, which can largely be attributed to its substantial GDP, which helped it to increase the level of intra-export during the period 1998-2008.

\section{Oman:}

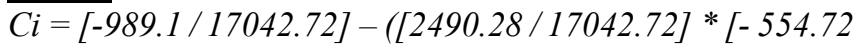

/ 17042.72])

$\boldsymbol{C} \boldsymbol{i}=\mathbf{0 . 0 5 3 3}$

The negative result above indicates that Oman has a intensity in the intra-import with other GCC countries. Also we note its trade is more than Bahrain's intra-import.

\section{Qatar:}

$C i=[-521.68 / 23624.31]-([2625.16 / 23624.31] *$

[5655.61/23624.31])

\section{$\boldsymbol{C} \boldsymbol{i}=\mathbf{- 0 . 0 4 8 5}$}

As we noted in cases of Oman and Bahrain, the negative result above indicates that Qatar has a density in its intra-import. 


\section{Kuwait:}

$$
\begin{aligned}
& \overline{C i=[-1033.14 / 45946.57]-([2011.22 / 45946.57]} \text { * } \\
& [19544.57 / 45946.57]) \\
& \boldsymbol{C i}=\mathbf{0 . 0 4 0 9}
\end{aligned}
$$

The above result shows that Kuwait has a low intensity in intra-import in comparison to Qatar, Bahrain and Oman, which means that Kuwait is not active in the field of intra-trade and confirms that the Kuwaiti economy has a weak commercial relationship with other GCC countries.To facilitate the analysis, we can set the obtained results in the following figure, as follows:

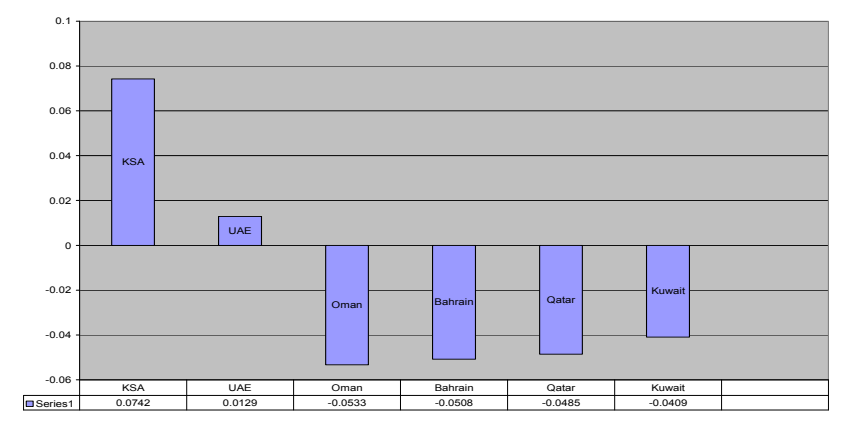

Fig. 3. Intra-trade in GCC - Average of period 1998-2008. Source: Formed by researcher based on the result of trade intensity.

Fig. 3 and its indicators shows the level of intra-trade intensity of the GCC countries during the period 1998-2008. It shows that Saudi Arabia is a major economy in terms of intra-trade intensity. The rest of the GCC countries, except the UAE, have obtained negative signals, which confirmed their intra-import density. In this regard Oman comes in the first level, then Bahrain, Qatar and Kuwait, which indicates that this negative group is reliant on Saudi Arabia as a main partner, as well as world markets to meet its various commodity needs.

\section{CONCLUSIONS}

Saudi Arabia has made a positive impact on the intra-trade, which means that the commodity products of this country have a competitive position compared to the rest of the GCC countries that import these products. However, according to the positive signals of intensity index, we see that Saudi Arabia and the UAE have a positive role in their non-oil sectors during the period 1998-2008.

In respect of the negative group (Bahrain, Qatar, Kuwait and Oman) we can say that these countries have not achieved a competitive advantage in their non-oil sectors. Therefore, these countries are still suffering from weakness of the level of non-oil industries and mainly depend on the oil sector, except Bahrain. In other words, the efforts of economic diversification in these countries are not reaching their objectives in this respect.

Finally, we conclude that the continued weakness of intra-trade in the GCC countries and the high level of oil share in GDP over the period 1998-2008 are the main reasons that led to the increase in the level of integration with the global economy, more than between GCC countries, meaning, that the efforts of the GCC countries to diversify the production structure have not achieved their aims except for Saudi Arabia and UAE, the economies of which still depend on the oil sector, which helped to increase the level of economic openness. However, it did not increase the level of intra-trade even though it was an important target of the unified economic policy of the GCC bloc.

\section{REFERENCES}

[1] S. Fischer, "Globalization and its Challenges," American Economic Review, vol.93, no.2, pp.12, May, 2003.

[2] D. Rodrik, "The New Global Economy and Developing Countries: Making Openness work," essay No.24, Overseas Development Council, and John Hopkins University Press, p.28, 1999.

[3] F. Alcala and A. Ciccone, Trade, extent of the market, and economic growth 1960-1996, University Murcia press, pp. 17, 2003.

[4] V. Spanue, "Liberalization of the International Trade and economic Growth: Implications for both developed and developing countries," Harvard University Press, pp 20-21, 2003.

[5] C.-H. Sohn, "A gravity model analysis of Korea's trade patterns and the effects of a regional trading arrangement," Korea Institute for International Economic Policy, working paper series, vol.2001-09, 2001.

[6] R. Falvey, N. Foster, and D. Greenway, "North - South Trade: Openness and Growth," University of Nottingham, United Kingdom, pp.1-11, 2001.

[7] C. Carrillo and C. A. Li, "Trade Blocks and the Gravity Model: Evidence from Latin American Countries," University of Essex press, UK, pp18-19, 2002.

[8] United Nations, ESCWA, External trade bulletin of the ESCWA region, eighteen issue, New York, pp.41-43, 2009.

[9] Arab monetary fund (AMF), 2009, Statistics of foreign trade, AMF, Kuwait www.amf.org.ae(www.amf.org.ae).

[10] SESRIC, (2009), Annual economic report on the OIC countries, Ankara, pp71-72.

[11] GCC, Secretariatgeneral, 2007 Statistical bulletin, vol. 16, (GCC, Secretariat general, 2007 Statistical bulletin, volume 16, p6.

[12] Ibid, p12.

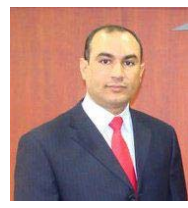

Ahmed Saddam Abdul Sahib was born in Basra,

1975

Second: Academic achievements:

1-B.Sc. in Economics , Faculty of Economics and

Administration - Basra University - 1997.

2-M.Sc in Economics, Faculty of Economics and Administration - Basra University- 2004.

3. Currently a PhD candidate at University of Malaya, Kuala Lumpur, Malaysia. (My study will be finished at the end of 2012).

Third: Profession:

Lecturer and Researcher at economy field - Arabian Gulf Studies Center - University of Basrah. IRAQ

Fourth: International Conferences:

1.Anadolu international conference in economics, University of Anadolu, 15-17 June, 2011. Title of presented paper (Analysis of intraregional trade and the impact of size of economy on commodity flows). Turkey.

2.The second annual conference of economic forum of entrepreneurship and international business. 2-4 Feb. 2012. Title of paper (Foreign trade, FDI, and their impact on growth in GCC countries), University of Ottawa. Canada.

3. International Conference on Human and Social Science, 23-24 March 2012.. Title of paper (Growth, FDI, Imports, and their impact on carbon dioxide emissions in GCC countries), Albania, Tirana.

4. International research conference on Economics, Social sciences \& Environmental issues, 6-7 March 2012. Thailand, Bangkok. Title of presentation: GCC economies and air pollution: A qualitative analysis to a carbon dioxide emissions

Sixth: Local conferences:

A presented referred paper in (9) local conferences in different Iraqi Universities and institutions.

Seventh: Books

Joint Author in publishing a book in Arabic language, Arab Unity studies centre, Lebanon, Beirut.

Joint author in publishing a book in Arabic language, Centre of Iraq studies, Iraq, Baghdad. 